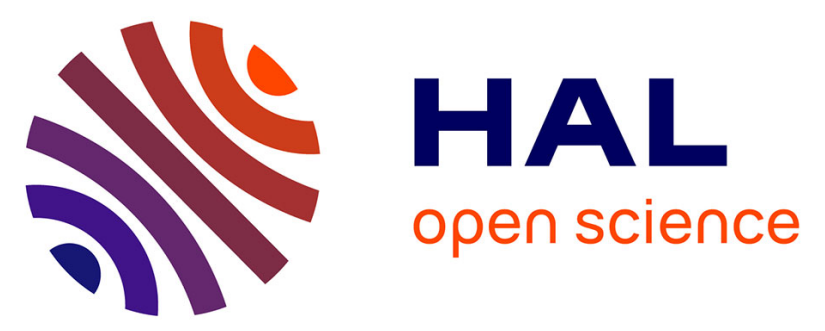

\title{
NEW TYPE OF DYE LASERS : POLYCHROMATIC SUPERBROADBAND TUNABLE LASER
}

\author{
A. Zhiglinskiy, A. Izmailov, G. Kund, I. Smirnova, I. Stuklov, P. Vorotnev
}

\section{To cite this version:}

A. Zhiglinskiy, A. Izmailov, G. Kund, I. Smirnova, I. Stuklov, et al.. NEW TYPE OF DYE LASERS : POLYCHROMATIC SUPERBROADBAND TUNABLE LASER. Journal de Physique IV Proceedings, 1991, 01 (C7), pp.C7-721-C7-724. 10.1051/jp4:19917195 . jpa-00250875

\section{HAL Id: jpa-00250875 https://hal.science/jpa-00250875}

Submitted on 1 Jan 1991

HAL is a multi-disciplinary open access archive for the deposit and dissemination of scientific research documents, whether they are published or not. The documents may come from teaching and research institutions in France or abroad, or from public or private research centers.
L'archive ouverte pluridisciplinaire HAL, est destinée au dépôt et à la diffusion de documents scientifiques de niveau recherche, publiés ou non, émanant des établissements d'enseignement et de recherche français ou étrangers, des laboratoires publics ou privés. 


\title{
NEW TYPE OF DYE LASERS: POLYCHROMATIC SUPERBROADBAND TUNABLE LASER
}

\author{
A.G. ZHIGLINSKIY, A.M. IZMAILOV, G.G. KUND, I.A. SMIRNOVA, I.G. STUKLOV \\ and P.A. VOROTNEV \\ Physical Research Institute, Ulianovskaja 1, Petrodvoret, Leningrad 198904, USSR
}

\begin{abstract}
The new polychromatic superbroadband turable dye leser is investigated. Main spectral features of such laser are presented. The possible apolication field is described.
\end{abstract}

1. Introduction.

The new type laser with polychromatic beforehand given spectrun radiation was suggested in /1/. In this paper spectral properties of such laser are investigeted and mein its characteristics are described.

2. Description of the characteristics of a new laser.

In respect to the traditional lasers the main distinction of polychromatic ones is the modes competition violation. It is achieved by means of different wavelengths generation chanals separation and ensuring of the positive feedback for all the expected wavelengths simultaneousely. For these principals realisation the new type laser cavity was developed, which was called the cavity with self reconstructed points. Every point emitting the light and placed on the appropriate plane which is situated inside the resonator is reconstructed to itself after each full pass of radiation through the laser of such type. Theoretical investigation of the cavity with self reconstructed points was based on the method of matrix optics. Requirments for existance of points reconstruction to itself in the cavity were discove- 
red from which it is seen that it is possible to construct such cavities with conventional optical elenents. Regiong of such cavity stability was found also.

Different wavelength radiation is eritted by different parte of active mediun in developed laser. It allows to violate the modes comptition that gives the possibility to widen the laser generation spectrua and to obtain the several wavelengths radiation or generation in the several parts of continuurn simultaneousely, to ture independently generation lines, their relative intensities and to form an expected spectral distribution of lasing intensity. It is interesting to mention that in this laser dispersive element is used not for sharpening of the lasing spectrum but for its brosdening.

The spectral region in which the several wavelengths lasing is possible is determined by the amplification band of used active medium and is situated in the interval of 400-700 $\mathrm{nm}$. Under the nesessity this spectral interval can be widened and shifted to the near UV or IR region.

The laser can generate in three wavelengths simultaneousely or in three parts of continuum. (The number of similteneous generation wavelengths depends on pumping power and can be increased by corresponding pumping power increase.) The generation lines can be grouped in the determinate spectral region or they can be distributed in all visible spectrum in arbitrary beforehand given way, i.e. can be coordinated with the spectra of atoms or molecules under investigation. The generation spectrum modification is realised without replacing of an active medium or any laser's elements or without realingment of its cavity.

The lasing with very broad continuous spectrum is also possjble. Under the enough pumping power the generation continuum wiath can reach $0.6-0.8$ of the active medium luminescence spectrum width. For instance, under the using excimer laser with power of $5 \mathrm{MWt}(\boldsymbol{\lambda}=303 \mathrm{~nm})$ for pumping of active medium which is ethanol solution of rhodamine-6G and oxasin-1? mixture, the lasing continuum width can be up to $150 \mathrm{~nm}$. That is mush broader than in the traditional dye laser with nondispersive cavity. The continum width can be increased by usage of two active media and by means of the 
pumping power increase. The measurment of the continum width was fulfiled by method of heterochrome photometrie of polychromatic laser radiation $/ 2 /$.

Under the nessesity the laser's generation sfectrum car be complicated. For exemple we have got the linear and continuum simultaneous lasing or linear spectrum in the background of continuum. Particularly with the help of such lasers simulation of different light sources is possible: natural light rodelying of solar, daylight; industrial sources.

The lasing linewidth ( without the intracavity interferometre) is 0.1-0.3nm. By means of intracavity interferometre the further narrowing of generation linewidth is possible. Thus linewidth decreases up to the $0.005 \mathrm{~nm}$ when lasing tuning is broadband (all the visible spectrum). The linewidth is up to $0.001 \mathrm{~nm}$ in the case narrowband (100nn) tuning range ( or in the case when generating lines lay in three respectively narrow ( $20 \mathrm{~nm}$ ) spectral intervals situated in the nessesary spectral region $)$.

The frequency stability during the working day is not. worser than the monochromatisation degree of generating radiation. This concerns both the case of lasing with the intracavity interferometre and without it.

The pure dyes and the mixtures as well were used as an active medium. In the first case the higher generation power was obtained, in the second case the spectral region in which the simultaneaus lasing in several wavelengths is possible can be widened simplier.

The active medium can be pumped by the conventional laser usualiy used for the active medium pumping in the traditional dye lasers, e.g. nitrogen or excimer lasers or UV harmonics of solid state lasers. The repetition rate of lasing pulses is determined by the pumping laser pulses repetition rate and can reach $10 \mathrm{~Hz}$ under the pumping power of $200 \mathrm{kWt}$ without dye circulation or cooling; under the dye circulation - up to $10 \mathrm{~Hz}$ ( the average pumping power is $2.5 \mathrm{Wt}$, the pulse power is $20 \mathrm{kWt}$ - the copper laser pumping).

By means of balance equations decision the output ra diation spectrum of such lasers is calculated. Calculations 
were fulfilied both for linear and continuura lasing. In both cases calculated and measured spectral distributions of emitted energy are in satisfactory agreement.

3. Fields of Application of polichromatic lasers.

The possibility of the demanded generation spectrum formation in the broadband spectral region widens the oppotunities of the laser and intracavity spectroscopy, photochemistry, multicomponent plasma holographic diagnostics. Such lasers application will allow to populate simultareousely several expected atomic or molecular levels, to carry out the absorbtion mesurements in the broadband spectral region, to get the information about different atoms, molecules, ions concentration in the plasme sinultaneousely. The polychromatic lasers can be used for highly excited atoms investigation, in the stepwise and multyphoton processes researching, for information transfer, in medicine.

4. Conclusions.

Thus the new type of dye lasers is investigated. The possibility of the polychromatic tunable lasing in the extremely broadband spectral region is shown. Unusual spectral characteristics of developed lasers open new possibilities in different fields of laser application.

1/ Izmailov A.M., Smirnova I.A., Zhiglinsky A.G., Vestnik LGU, Ser.4, N2 (1991), 8 .

(2) Izmailov A.M., Kund G.G., Smirnova I.A., Vorotnev P.A., JNPFK, USSR, V.36, N3 (1991), 249. 